\title{
National Survey Regarding the Timing of Endoscopic Procedures during the Covid-19 Pandemic
}

\author{
José Daniel Marroquín-Reyes
}

Department of Gastrointestinal Endoscopy, Instituto Nacional de Ciencias Médicas y Nutrición Salvador Zubirán, Mexico City, Mexico

\section{Sergio Zepeda-Gómez}

Division of Gastroenterology, University of Alberta, Edmonton, Alberta, Canada

\section{Alejandra Tepox-Padrón}

Department of Gastrointestinal Endoscopy, Instituto Nacional de Ciencias Médicas y Nutrición Salvador Zubirán, Mexico City, Mexico

\section{Mariana Quintanar-Martínez}

Department of Gastrointestinal Endoscopy, Instituto Nacional de Ciencias Médicas y Nutrición Salvador Zubirán, Mexico City, Mexico

\section{Omar Edel Trujillo-Benavides}

Department of Gastrointestinal Endoscopy, General Hospital, IMSS, Puerto Vallarta, Jalisco, Mexico

Félix I. Téllez-Avila ( $\sim$ felixtelleza@gmail.com )

Department of Gastrointestinal Endoscopy, Instituto Nacional de Ciencias Médicas y Nutrición Salvador Zubirán, Mexico City, Mexico

\section{Research Article}

Keywords: COVID-19, Endoscopic procedures

Posted Date: December 1st, 2020

DOl: https://doi.org/10.21203/rs.3.rs-118352/v1

License: (c) (i) This work is licensed under a Creative Commons Attribution 4.0 International License. Read Full License

Version of Record: A version of this preprint was published at Surgical Endoscopy on January 25th, 2021. See the published version at https://doi.org/10.1007/s00464-021-08290-8. 


\section{Abstract}

Background: During the COVID-19 pandemic, several questions have arisen about which endoscopic procedures (EPs) must be performed and which ones can be postponed. The aim of this study was to conduct a nationwide survey regarding the appropriate timing of EPs during the COVID-19 pandemic.

Methods: This prospective study was performed through a nationwide electronic survey. The survey consisted of 15 questions divided into three sections. The first evaluated the agreement for EPs classified as "time sensitive" and "not time sensitive". Two other sections assessed "high-priority" and "low-priority" scenarios. Agreement was considered when $>75 \%$ of respondents answered a question in the same direction.

Results: The response rate was $27.2 \%$ (214/784). Among the respondents, agreement for the need to perform EP in $<72$ hours was only reached for variceal bleeding (93.4\%). Dysphagia with alarm symptoms was the scenario in which the highest percentage of physicians $(95.9 \%)$ agreed that an EP needed to be performed within a month. Less than $30 \%$ of endoscopists would perform an EP within the first 72 hours for patients with mild cholangitis, non-variceal upper gastrointestinal bleeding without hemodynamic instability, or severe anaemia without overt bleeding. In time-sensitive clinical scenarios suggestive of benign disease, none of the scenarios reached agreement in any sense. Among the timesensitive clinical scenarios suggestive of malignancy, $>90 \%$ of the surveyed respondents considered that EP could not be postponed for $>8$ weeks.

Conclusions: There was no consensus among endoscopists about the timing of EPs in patients with pathologies considered time sensitive or in those with high-priority pathologies. Agreement was only reached in five $(17 \%)$ of the evaluated clinical scenarios.

\section{Background}

During the COVID-19 pandemic, health services around the world have redirected their resources to the care of these patients [1]. Prior to the pandemic, 17.7 million endoscopic procedures (EPs) were performed annually in the United States, corresponding to $5.6 \%$ of the US population[2], however, endoscopy departments have experienced a reduction in the number of EPs performed during the pandemic $[3,4]$. One of the most important questions during the pandemic and in the return to normality is which EPs should be prioritised[5]. Different international societies have published recommendations to guide endoscopists on this matter[6-8]. Some EPs can be systematically performed or postponed; however, others must be assessed on a case-by-case basis, weighing the trade-offs of the medical indication or necessity with the COVID-19 risks. For these clinical scenarios, the American Gastroenterological Association (AGA) proposes the classification of EPs as those that are "time sensitive" and "not time sensitive" and, on this basis, recommends prioritising time-sensitive procedures for disorders that can endanger the life of the patient or cause permanent organ dysfunction or disorders with a risk of metastasis or disease progression. All gastrointestinal $(\mathrm{Gl})$ disorders that do not meet these 
definitions are considered "not time sensitive"[6]. However, these definitions could be debated [9]. The European Society for Gastrointestinal Endoscopy (ESGE) recommends the classification of these procedures according to the specific clinical features (e.g., uninvestigated dyspepsia without alarm features, Barrett's oesophagus with high-grade dysplasia) and their priority (e.g., high priority, low priority) [7]. At the moment, there is no clear behaviour among endoscopists in clinical practice regarding which procedures to perform or postpone during the COVID-19 pandemic. We hypothesised that there would be a high level of heterogeneity among respondents regarding whether an EP is considered time sensitive and high priority.

The aim of this study was to conduct a nationwide survey regarding when to perform EPs considered time sensitive and/or high priority during the COVID-19 pandemic.

\section{Methodology}

A prospective study was conducted through an electronic survey sent to members of the Mexican Association for Gastrointestinal Endoscopy (MAGE). A 15-question Spanish questionnaire was designed using Google's Electronic Forms tool to find out the opinion of endoscopists at a national level regarding the times they deemed appropriate to perform EPs classified in accordance with the AGA and ESGE. Responses were collected over a 15-day period, during which two separate emails were sent: an initial invitation and a second reminder a week later. The survey consisted of 15 questions divided into three sections. The first section evaluated endoscopists' opinion of time-sensitive and non-time-sensitive procedures according to AGA definitions[6]. The other two sections assessed respondents' views on highpriority and low-priority scenarios according to ESGE definitions [7]. For the purpose of this work, agreement was deemed to exist when $>75 \%$ of respondents answered a question in the same way. In the case of time-sensitive or non-time-sensitive procedures, questions were raised regarding which procedures should be performed within a maximum period of 72 hours (urgent), and which could be postponed for more than 8 weeks without putting the patient at risk and with no risk of disease progression or an increase in the severity of symptoms (supplementary material Q1-3). In the following two sections, using the approach proposed by ESGE, respondents were asked about specific low- and high-priority clinical scenarios and about when these EPs should be performed ( $<1$ month, 1-2 months, 2-3 months, or "at the end of the pandemic"; supplementary material Q4-15). The definitions proposed by the ESGE were used for this item. Questions about obvious clinical scenarios where there was no doubt about whether or not to perform a study (e.g., patient with hematemesis or severe cholangitis and evidence of choledocholithiasis) were avoided.

A pilot study was conducted to validate the survey by inviting 30 MAGE members to determine the correct redaction of questions and deficiencies in response options. The questionnaire in its final format was sent to all AMEG members $(n=784)$.

The database was captured in Excel and the sample calculation was performed using Epiinfo® software. Knowing that the number of MAGE members in 2020 is 784, 258 participants were required for the survey 
to be representative, expecting a confidence level of $95 \%$. For the statistical analysis, absolute and relative frequencies were used with measures of central tendency and dispersion for a normal distribution. The SPSS v25 statistical package was used.

In order to answer the survey, consent was required. Data were handled anonymously and confidentially. The survey didn't include personal information and any details that could compromise anonymity were not gathered. The protocol was approved by the local ethics and investigation committee of National Institute of Nutrition Salvador Zubirán, Mexico City.

\section{Results}

The time taken to complete the survey averaged 5 minutes. The response rate was $27.2 \%(214 / 784$ endoscopists).

\section{Procedures classified as time sensitive and not time sensitive (questions 1-3 in survey)}

Regarding EPs that should be performed in $<72$ hours, agreement was only achieved for variceal bleeding (93.4\%). In patients with mild cholangitis, non-variceal upper gastrointestinal bleeding without hemodynamic instability, severe anaemia $(\mathrm{Hb}<7 \mathrm{~g} / \mathrm{dL})$ without overt bleeding, and lower $\mathrm{Gl}$ bleeding, $<30 \%$ of respondents considered it necessary to perform EP within the first 72 hours.

In clinical scenarios suggestive of time-sensitive benign diseases, respondents were asked whether postponing the EP $>8$ weeks could lead to disease progression or increased severity of symptoms, but none of the scenarios reached agreement among the respondents (supplementary material Q2-3). Furthermore, in cases of colonic adenoma $\geq 2 \mathrm{~cm}$ or endoscopic evaluation for suspected small bowel bleeding without hemodynamic instability, the participants agreed that an EP should not be performed within the 8-week period (Figure 1). In clinical scenarios suggestive of time-sensitive malignant disease, there was agreement among respondents that the EP should be performed within 8 weeks (Figure 2; supplementary material Q2-3).

\section{Procedures of low priority and high priority}

Table 1 shows the percentage of surveyed physicians who voted to perform endoscopic procedures considered "high" or "low" priority in given periods of time. In general, those scenarios suggestive of malignancy were more frequently considered to be candidates for earlier EPs. Dysphagia with alarm features was the scenario in which the highest percentage of physicians $(95.9 \%)$ voted that the procedure be performed within a month. Conversely, gastroesophageal reflux disease without alarm features was the scenario in which the highest percentage of physicians surveyed (38\%) were in favour of postponing the EP >3 months. 


\section{Discussion}

In this initial survey regarding the adequate timing of endoscopy among different clinical scenarios, there was no consensus among endoscopists about the timing of EPs in patients with time-sensitive and highpriority pathologies.

Although there are two classifications for EPs during the COVID-19 pandemic, in our study we observed considerable heterogeneity in opinions among endoscopists when deciding which EPs to prioritise. In the current national survey, physicians were asked about the timing of EPs classified as "time sensitive" versus "not time sensitive" or "high priority" versus "low priority". Among the clinical scenarios of gastrointestinal bleeding (upper, lower and small bowel), only variceal bleeding had $>75 \%$ agreement among the surveyed endoscopists to be performed within 72 hours. In scenarios with potentially progressive diseases (ulcerative colitis, Barrett's oesophagus with high-grade dysplasia, pancreatic mass, etc.) there were different opinions regarding the performance of such procedures $<8$ weeks as recommended by AGA and $<12$ weeks as recommended by ESGE $[6,7]$. None of the scenarios reached $75 \%$ agreement. The only clinical scenarios in which $>75 \%$ of respondents agreed to postpone the EP by at least 8 weeks were for the surveillance of gastric intestinal metaplasia without dysplasia and uninvestigated dyspepsia without alarm features.

In the case of EP for pathologies considered to be elective (iron deficiency anaemia, GERD) no uniformity was found regarding the appropriate time to perform EP. Only in cases of uninvestigated dyspepsia with alarm features and ampulloma there was $50-60 \%$ agreement to perform EP in the first 4 weeks. This last item is very interesting because the ESGE considers that ampullectomy could be considered as "Iow priority" and can be postponed beyond 12 weeks. In cases of dysphagia with alarm features and an incidental finding of a GI tumour on CT scan, $>75 \%$ of respondents considered that the EP should be performed in the first 4 weeks. It can be noted that the common factor for all these clinical scenarios is that all of them have the probability of a malignancy. Therefore, the clinical scenarios suggestive of malignancy showed the highest rate of agreement among the surveyed endoscopists to perform the EP.

It is interesting to us that, out of the 29 clinical scenarios proposed, agreement was reached in only five $(17 \%)$ of them (three high-priority and two low-priority scenarios). This is similar to the results published by Bilal et al. (9). In their study, the authors found only three of $16(18.7 \%)$ scenarios in which greater than $70 \%$ of gastroenterologists agreed on procedure timing. Although the survey method was different to the one used in our study, the results are very similar, and we consider that this percentage will be close if other surveys are done on this topic.

It is difficult to understand the reasons why the answers in our survey have important variations in comparison to the recommendations made by the AGA and ESGE. In our survey, all the respondents are from a developing country with limitations regarding accessibility to hospitals, endoscopy rooms and qualified endoscopy personnel (even before COVID-19), so the definition of semi-urgent endoscopy may be narrow. It is important to note that our survey was carried out during the worst moment of the COVID19 pandemic in our country, so it is possible that application of the same survey at a different time could 
lead to variations in the answers. At the time of the survey, the lack of personal protective equipment in our hospitals could have been associated with more strict criteria to classify procedures.

The limitations of our study were the small sample size and that only surveys of MAGE members were included. Our study has some strengths that are worth noting. Despite the small sample size, the response rate $(27.2 \%)$ was good and this is a national study in health professionals of gastroenterology. Additionally, since the response rate of the survey included a quarter of the members of the MAGE, we could have a good picture about the priorities about timing of EP during the COVID pandemic. It should be emphasised that the clinical scenarios used in this survey are the same as those used by the AGA and ESGE, thereby facilitating comparison with endoscopists from different countries. Therefore, we may consider that the opinion of the endoscopists surveyed for this study may not be that different from other occidental countries affected by the pandemic.

\section{Conclusions}

According to our data, there is no consensus among endoscopists about the timing of EP in patients with time-sensitive and high-priority pathologies. In our proposed clinical scenarios, agreement was only reached in five (17\%; three high-priority and two low-priority scenarios).

\section{Declarations}

Author contributions: Téllez-Ávila Fl and Marroquín-Reyes JD, designed the study; Téllez-Ávila Fl, Marroquín-Reyes JD, Zepeda-Gómez S, Tepox-Padrón A, Quintanar-Martínez M and Trujillo-Benavides OE organised the report; Téllez-Ávila Fl, Marroquín-Reyes JD and Zepeda-Gómez S wrote the manuscript; and Téllez-Ávila FI, Marroquín-Reyes JD, Zepeda-Gómez S, Tepox-Padrón A, Quintanar-Martínez M and TrujilloBenavides $\mathrm{OE}$ read the manuscript and made important intellectual contributions.

Disclosure: All authors have no financial relationships relevant to this publication to disclose.

\section{References}

[1] Lai C-C, Wang C-Y, Wang Y-H, Hsueh S-C, Ko W-C, Hsueh P-R. Global epidemiology of coronavirus disease 2019 (COVID-19): disease incidence, daily cumulative index, mortality, and their association with country healthcare resources and economic status. Int J Antimicrob Agents 2020;55:105946. https://doi.org/10.1016/j.ijantimicag.2020.105946.

[2] Peery AF, Crockett SD, Murphy CC, Lund JL, Dellon ES, Williams JL, et al. Burden and Cost of Gastrointestinal, Liver, and Pancreatic Diseases in the United States: Update 2018. Gastroenterology 2019;156:254-272.e11. https://doi.org/10.1053/j.gastro.2018.08.063. 
[3] Forbes N, Smith ZL, Spitzer RL, Keswani RN, Wani SB, Elmunzer BJ, et al. Changes in Gastroenterology and Endoscopy Practices in Response to the Coronavirus Disease 2019 Pandemic: Results From a North American Survey. Gastroenterology 2020;159:772-774.e13. https://doi.org/10.1053/j.gastro.2020.04.071.

[4] Chen Y, Yu Q, Farraye FA, Kochhar GS, Bernstein CN, Navaneethan U, et al. Patterns of endoscopy during COVID-19 pandemic: a global survey of interventional inflammatory bowel disease practice. Intest Res 2020. https://doi.org/10.5217/ir.2020.00037.

[5] Hennessy B, Vicari J, Bernstein B, Chapman F, Khaykis I, Littenberg G, et al. Guidance for resuming GI endoscopy and practice operations after the COVID-19 pandemic. Gastrointest Endosc 2020;92:743747.e1. https://doi.org/10.1016/j.gie.2020.05.006.

[6] Sultan S, Lim JK, Altayar O, Davitkov P, Feuerstein JD, Siddique SM, et al. AGA Rapid Recommendations for Gastrointestinal Procedures During the COVID-19 Pandemic. Gastroenterology 2020;159:739-758.e4. https://doi.org/10.1053/j.gastro.2020.03.072.

[7] Gralnek IM, Hassan C, Beilenhoff U, Antonelli G, Ebigbo A, Pellisè M, et al. ESGE and ESGENA Position Statement on gastrointestinal endoscopy and the COVID-19 pandemic. Endoscopy 2020;52:483-90. https://doi.org/10.1055/a-1155-6229.

[8] Chiu PWY, Ng SC, Inoue H, Reddy DN, Ling Hu E, Cho JY, et al. Practice of endoscopy during COVID19 pandemic: position statements of the Asian Pacific Society for Digestive Endoscopy (APSDE-COVID statements). Gut 2020;69:991-6. https://doi.org/10.1136/gutjnl-2020-321185.

[9] Bilal M, Simons M, Rahman AU, Smith ZL, Umar S, Cohen J, et al. What constitutes urgent endoscopy? A social media snapshot of gastroenterologists' views during the COVID-19 pandemic. Endosc Int Open 2020;8:E693-8. https://doi.org/10.1055/a-1153-9014.

\section{Table}




\begin{tabular}{|c|c|c|c|c|}
\hline Scenario & $\begin{array}{l}1 \text { month } \\
\mathrm{n}(\%)\end{array}$ & $\begin{array}{l}1-2 \\
\text { months } \\
\mathrm{n}(\%)\end{array}$ & $\begin{array}{l}2-3 \\
\text { months } \\
\mathrm{n}(\%)\end{array}$ & $\begin{array}{l}>3 \\
\text { months } \\
\mathrm{n}(\%)\end{array}$ \\
\hline Iron deficiency anaemia without overt bleeding & $\begin{array}{l}59 \\
(27.2)\end{array}$ & $77(36.4)$ & $42(19.7)$ & $36(16.6)$ \\
\hline Refractory GERD without alarm features & $15(7.2)$ & $54(25.1)$ & $63(29.5)$ & $82(38.0)$ \\
\hline EV ligation for eradication protocol & $\begin{array}{l}42 \\
(19.7)\end{array}$ & $87(40.8)$ & $49(22.8)$ & $36(16.6)$ \\
\hline Asymptomatic biliary stricture & $\begin{array}{l}101 \\
(47.4)\end{array}$ & $62(28.7)$ & $35(16.4)$ & $16(7.4)$ \\
\hline Non-urgent BS replacement & - & - & $129(59.7)$ & $85(39.5)$ \\
\hline $\begin{array}{l}\text { Granular LECL resection without suspected } \\
\text { carcinoma }\end{array}$ & $\begin{array}{l}29 \\
(13.8)\end{array}$ & $100(46.7)$ & - & $85(39.5)$ \\
\hline Dyspepsia with alarm features & $\begin{array}{l}142 \\
(65.8)\end{array}$ & $33(15.6)$ & $23(10.8)$ & $16(7.7)$ \\
\hline Incidental GI tract tumour in imaging studies & $\begin{array}{l}165 \\
(77.2)\end{array}$ & - & $45(20.6)$ & $4(2.1)$ \\
\hline Ampuloma & $\begin{array}{l}118 \\
(55.0)\end{array}$ & $56(26.4)$ & $32(14.6)$ & $8(3.8)$ \\
\hline Dysphagia with alarm features & $\begin{array}{l}205 \\
(95.9)\end{array}$ & $8(3.7)$ & - & $1(0.3)$ \\
\hline
\end{tabular}

\section{GERD, gastroesophageal reflux disease; EV, oesophageal varices; BS, biliary stent; LECL, laterally extended colonic lesion; GI, gastrointestinal.}

\section{Figures}




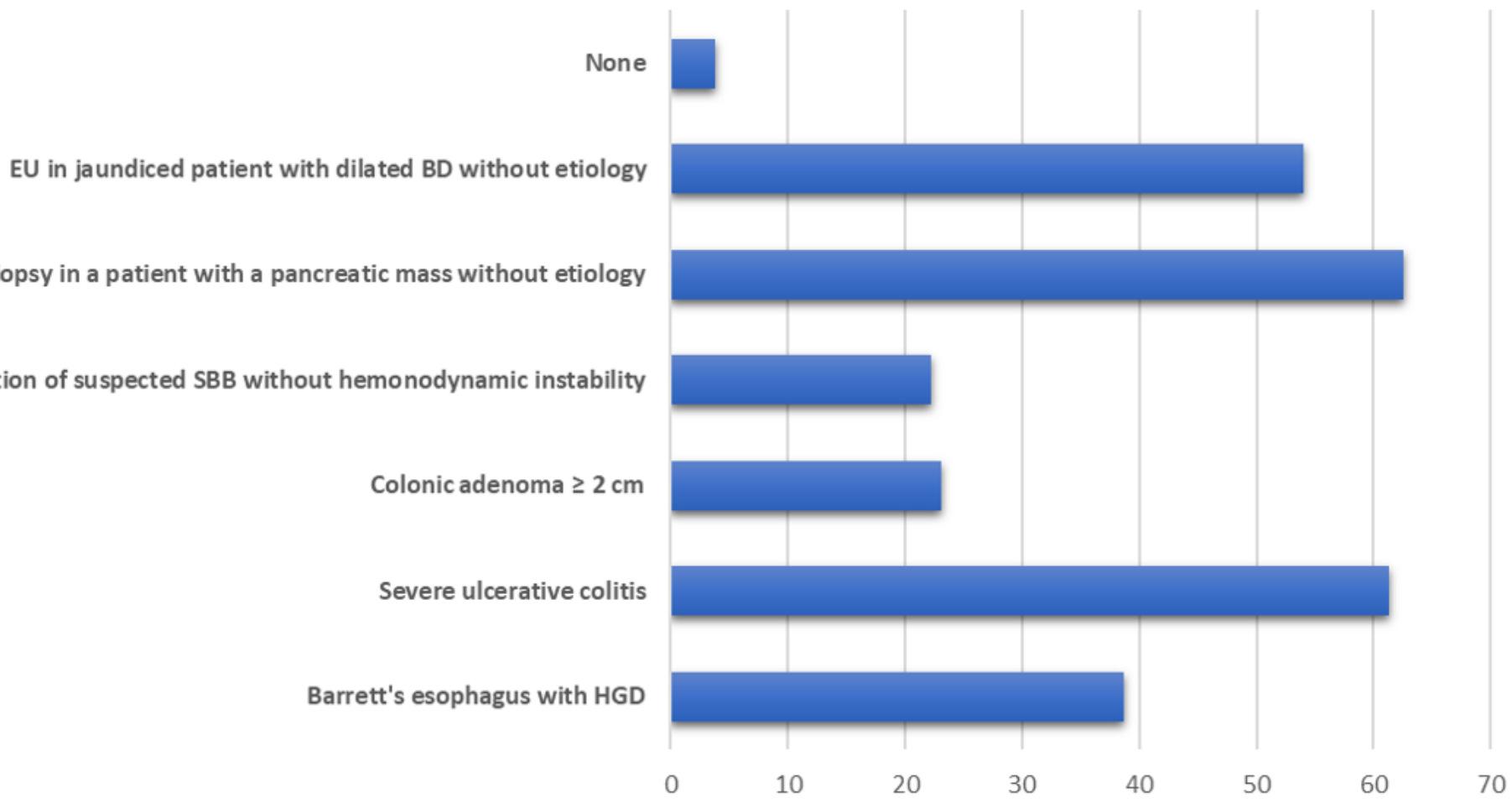

\section{Figure 1}

In which one do you consider that postponing EP $>8$ weeks can lead to disease progression that puts the patient at risk or an increase in the severity of symptoms? EP, endoscopic procedure; EU, endoscopic ultrasound; BD, bile duct; SBB, small bowel bleeding; HGD, high grade dysplasia.

EU in jaundiced patient with dilated BD without etiology

EU biopsy in a patient with a pancreatic mass without etiology

Evaluation of suspected SBB without hemonodynamic instability

Colonic adenoma $\geq 2 \mathrm{~cm}$

Severe ulcerative colitis

Barrett's esophagus with HGD

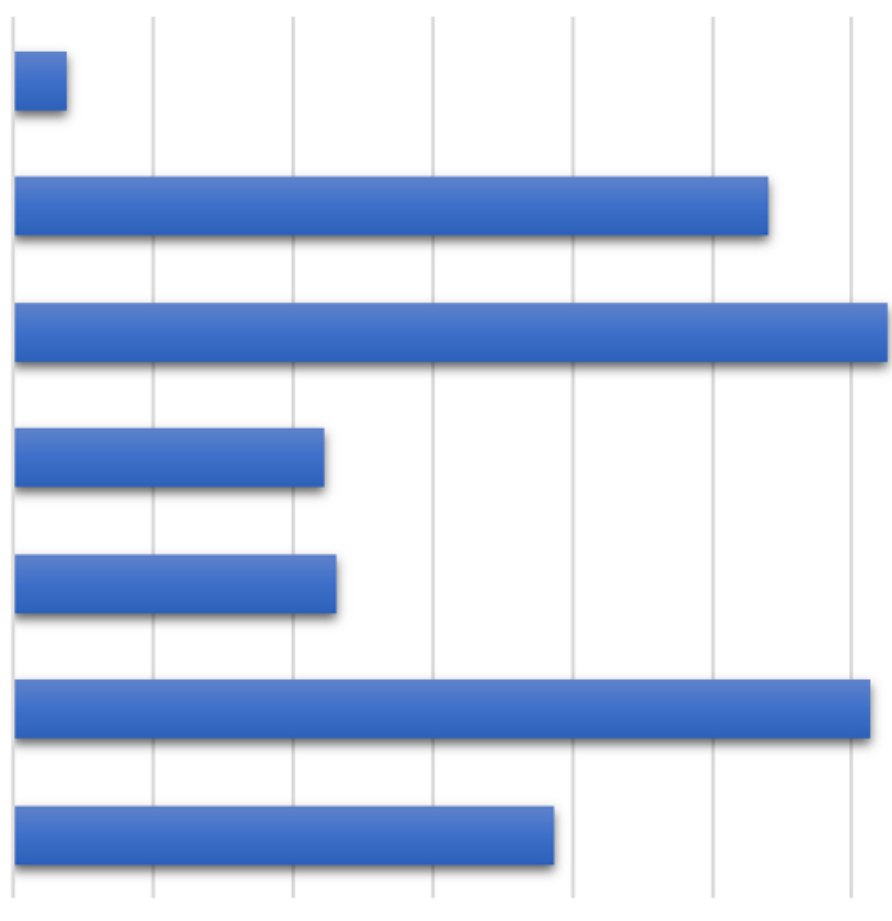

0

10

20

30

40

50

60

\section{Figure 1}


In which one do you consider that postponing EP > 8 weeks can lead to disease progression that puts the patient at risk or an increase in the severity of symptoms? EP, endoscopic procedure; EU, endoscopic ultrasound; BD, bile duct; SBB, small bowel bleeding; HGD, high grade dysplasia.

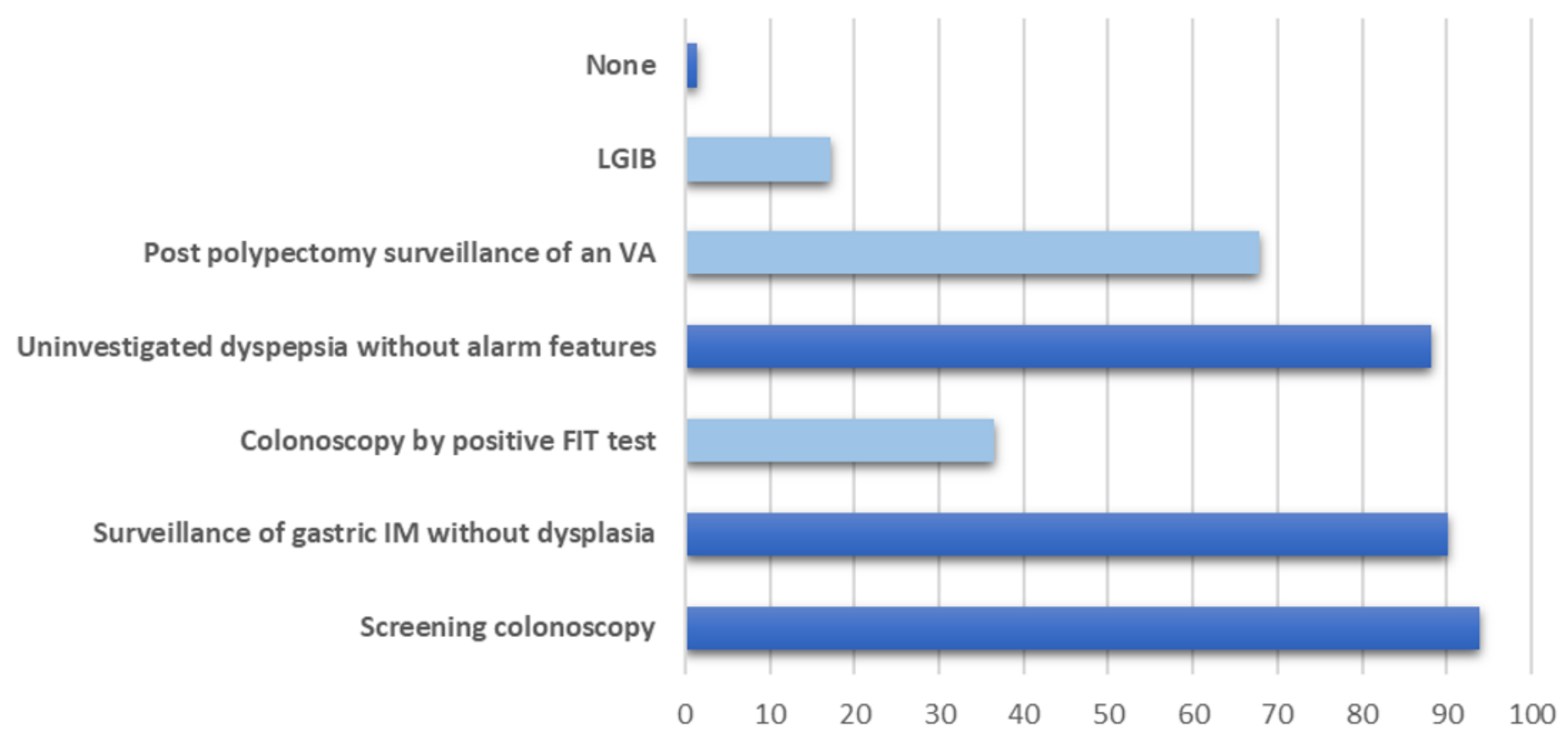

\section{Figure 2}

In which one do you think it is possible to postpone EP > 8 weeks without a negative impact on the patient's health? EP, endoscopic procedure; LGIB, lower gastrointestinal bleeding; VA, villous adenoma; FIT, faecal immunochemical test; IM, intestinal metaplasia.

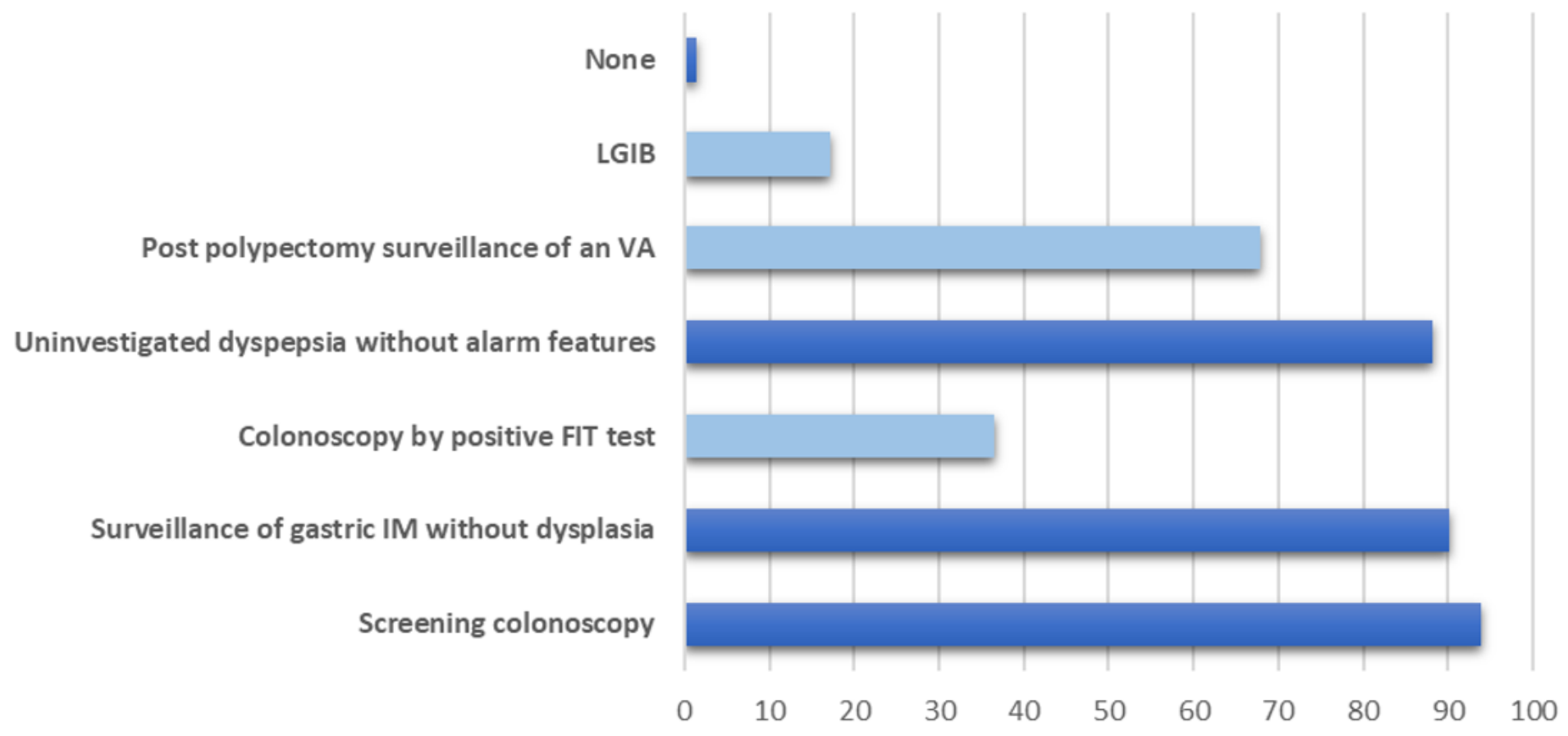

Figure 2 
In which one do you think it is possible to postpone EP > 8 weeks without a negative impact on the patient's health? EP, endoscopic procedure; LGIB, lower gastrointestinal bleeding; VA, villous adenoma; FIT, faecal immunochemical test; IM, intestinal metaplasia.

\section{Supplementary Files}

This is a list of supplementary files associated with this preprint. Click to download.

- Supplementarymaterial.docx

- Supplementarymaterial.docx 